\title{
Unveiling Special Policy Regime, Judgment And Taylor Rules In Tunisia
}

\author{
Yosra Baaziz, FSEG Mahdia, Tunisia \\ David Heller, ISC Paris, France \\ Moez Labidi, University of Monastir, Tunisia \\ Amine Lahiani, LEO-University of Orleans, France
}

\begin{abstract}
Given limited research on monetary policy rules in revolutionary countries, this paper challenges the suitability of the Taylor rule in characterizing the monetary policy behavior of the Tunisian Central Bank (BCT), especially in turbulent times.

More specifically, we investigate the possibility that the Taylor rule should be formulated as a threshold process and examine the validity of such nonlinear Taylor rule as a robust rule for conducting monetary policy in Tunisia.

Using quarterly data from 1998:Q4 to 2013:Q4 to analyze the movement of nominal short-term interest rate of the $B C T$, we find that the nonlinear Taylor rule improves its performance with the advent of special events providing thus a better description of the Tunisian interest rate setting. In particular, our results show that the adoption of an appropriate nonlinear approach leads to a reduction in the errors of 150 basis points in 1999 and 2009, and 60 basis points in 2011, relative to the linear approach.
\end{abstract}

Keywords: Policy Rule; Central Bank; Exchange Rate; Taylor Rule; Nonlinearity

\section{INTRODUCTION}

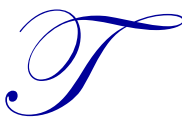

he debate on whether central banks should follow a rule rather than a discretionary monetary policy has not been settled between academics and policymakers. Central bankers and monetary policy theorists have been trying for several years to find an intermediate area between absolute discretion that adopts inflationary bias attributed to constancy problem (Akerlof, 1970; Mankiw, 1990; Romer, 2000; Stiglitz, 2000), and the use of purely rule-based framework, which is unable to face unexpected structural changes (Kydland and Prescott, 1977; Friedman, 1959; Barro and Gordon, 1983; McCallum, 1988; Bernanke and Woodford, 1997; Ball, 1999; Mishkin, 1999; Svensson, 2003).

The constrained discretion framework, advanced by Bernanke and Mishkin (1997), successfully addresses the issue of inflation targeting based on low and stable inflation target and increased communication with public in accordance with the goals of monetary policymakers. This hybrid ${ }^{1}$ regime allows policymakers to adopt as they learn, while remaining systematic and transparent thanks to the predetermined targets. Under constrained discretion, the central bank is free to use any suitable tool to stabilize disturbances, with the appropriate wariness due to the imperfect knowledge of the economy and the effects of policy (Bernanke, 2003).

To be effective, regulation must be dynamically adjusting to changing behavior. However, such dynamic conduct has to be constrained to the extent of the reputation for keeping inflation firmly under control. Despite the many discussions, no consensus has yet emerged on this hybrid regime.

In practice, the superiority of the rules of discretion is considered, in recent decade, as the guiding ideology for the conduct of monetary policy under the guise of improving the overall macroeconomic performance. One of the most

${ }^{1}$ Hybrid regime refers to countries that conducted inflation-focused monetary policies (Bernanke and Mishkin, 1997). 
widespread rules in the literature is the Taylor rule (1993), which postulates the systematic and stable reaction of short-term interest rates to deviations of inflation and output gap from their targets.

However, there is still an ongoing debate on how to model these decisions empirically. This original Taylor rule has undergone various modifications as researchers attempted to make it more realistic and appropriate.

Some researchers include a lagged interest rate term to model the monetary policy inertia or interest rate smoothing behavior (Clarida et al, 1998). Others consider an augmented version of the linear Taylor rule by enclosing other variables in the conduction mechanism of monetary policy. Svensson (2003) proposes an extension of the Taylor rule by incorporating the exchange rate in a rule designed for small open economies. His conclusion is in line with that of Batini et al (2001) who show that the descriptive power of the Taylor rule augmented by the exchange rate variable is higher than the standard Taylor rule for small open economies (i.e. UK).

Although this linear interest rate rule recognizes nowadays a renewed interest, it is not fully adapted to an environment strongly characterized by uncertainty. Indeed, in such a context, the evolution of monetary policy over a long period may entail structural changes in the behavior of monetary authorities. The failure to take into account these changes may bias the results. Clearly, the linear model is unable to capture changes in relative preferences of monetary authorities over time and describe perfectly the structure of the economy.

This opens the way to seek alternative policy rules that can provide better results even though macroeconomic structural changes occur continuously and/or the central bank has imperfect knowledge of the dynamic of the economy. Therefore, the recent literature tries to take nonlinearity into account.

A few works on monetary policy are laid on nonlinear models. These models assume that the response of interest rate to economic conditions is nonlinear time-variant because central bank preferences are not quadratic and the aggregate supply reaction is nonlinear.

Mishkin (2011) questions the traditional quadratic-linear framework when financial markets are disrupted and puts forward the arguments for replacing it by nonlinear dynamics leading to a nonlinear optimal monetary policy.

In addition, almost all of recent studies focusing on nonlinear Taylor rule are limited to industrialized countries, especially US (Lee and Son, 2013; Olsen et al, 2012; Conrad and Eife, 2012), UK (Bruggemann and Riedel, 2011), ECB (Castro, 2011) and Canada (Komlan, 2013) to name few.

Thus, the purpose of this paper is to evaluate the behavior of monetary authorities in Tunisia in response to changes in macroeconomic variables over time using the Logistic Smooth Transition (LSTR) model in order to investigate a possible deviation from the simple instrument rule and identify the specific rule that characterizes the special regime.

The LSTR model is appropriate to capture asymmetry, heterogeneity and time-varying monetary policy reaction. Parameters change is governed by a transition variable that traces well heterogeneity and specificity of each country and even each study period. Therefore, it may be a more realistic description of the systematic response of the monetary authority to economic developments since heterogeneity between countries interferes with the reliability and validity of the linear model.

Accordingly, we investigate both linear and nonlinear Taylor-type monetary policy reaction functions in Tunisia using inflation, output gap, lagged interest rate and real effective exchange rate (REER). We also examine whether monetary policy following nonlinear Taylor rule model could provide additional information over a linear model and to what extent special regimes are not detected by a linear Taylor rule.

This paper contributes to current monetary debates through justifying why and when does the Central Bank adjust its policy rule, when fitted in the context of a revolutionary country, namely Tunisia. 
The remaining of the paper is organized as follows: section 2 reviews the existing literature on monetary policy rules. Section 3 describes the econometric methodology. Section 4 outlines the data. In section 5, the empirical analysis is performed and results are discussed. Section 6 is devoted to a robustness check analysis and misspecification tests of the nonlinear methodology. Section 7 summarizes the main conclusions of this paper.

\section{LITERATURE}

Much debate has been devoted recently to Time-Varying Parameter (TVP) specification of monetary policy rules and structural breaks in the Taylor rule. Several studies have attempted to capture changes in policy implementation by using different econometric approaches.

One possibility is to split the sample at the presumed break dates and estimate the monetary policy model in each subperiod separately. For instance, Judd and Rudebush (1998) illustrate whether the Fed behaves differently over time using ordinary least squares (OLS) and subsample analysis. Their results show that there are significant differences in the way monetary policy was conducted pre- and post-Paul Volker's appointment as chairman of the Fed in 1979. Similarly, Taylor (1999) divided his data sample into two subperiods: 1960:Q1 - 1979:Q4 (pre-Volker) and 1987:Q1 - 1997:Q3 (mandate Volker and Greenspan) and finds that the coefficient of inflation is greater than unity in the second subperiod, so that the Taylor Principle is verified only in the second subperiod. Clarida et al. (2000) consider the terms of Fed chairmen as defining different regimes using the GMM estimation technique to estimate monetary policy reaction functions of the G3 and E3 countries.

This view is supported by Orphanides (2004) who argues that institutional changes of Central banks correspond to structural instability of the reaction parameters of Taylor-type rule.

More recent research has questioned both this exogenous choice of subsamples and the characterization of the conduct of monetary policy as a pre-Volker and Volker- Greenspan regimes.

In this sense, Kim and Nelson (2006) argue that the conventional division of the sample on pre-Volker and VolkerGreenspan may mislead the empirical evaluation of US monetary policy since each subsample may contain more than one monetary regime.

An alternative is to apply an econometric model that allows time-varying parameters. Indeed, there are various methods dealing with time variability of parameters in the context of estimated monetary policy rule.

One popular methodology is the application of the Kalman filter to infer time-varying parameters. The Kalman filter formula, given by the linear recursive algorithm, has originally been applied by engineers and physicists to estimate the state of a noisy signal and subsequently adopted by statisticians and econometricians.

In particular, several studies used the Kalman filter to estimate policy rule with parameters varying in time (Boivin, 2006; Trecrocci and Vasalli, 2006). The Kalman filter incorporates the structural changes in monetary policy rule since it updates the inference on an unobservable state variable whenever new information on the observed measurement variable becomes available.

Trecocci and Vasalli (2006) estimate a forward looking Taylor rule for the United Kingdom, Germany, France, Italy and the United States using the Kalman filter approach. The objective is to conduct monetary policy in a dynamic and involving environment. They show that the time-varying parameters rule outperforms the standard Taylor rule as to their relative ability to track actual interest rate policies.

Boivin (2006) uses real-time data to estimate a forward-looking Taylor rule with TVP for United States using the Kalman filter. His conclusion follows those of Trecrocci and Vasalli (2006). Hence, the TVP Taylor rule performs well in capturing the policy shifts. 
Similarly, Elkhoury (2006) estimates a monetary policy rule with time-varying coefficient using a Kalman filter algorithm. He suggests that regression coefficients are time-varying and most of uncertainty comes from timevarying coefficients rather than from the pure monetary shock.

Mandler (2007) attempts to estimate a Taylor rule with TVP using maximum likelihood estimation technique via Kalman filter to predict uncertainty in the future values of the Fed's rate. He shows that the uncertainty associated with policy rule is mainly due to the variation over time of the parameters. This uncertainty is related to the purely monetary shocks and residual uncertainty.

However, the main drawback of the Kalman-filter methods is their over parameterization. This view is supported by Belsley and Kuti (1973) according to whom "a major limitation of Kalman filter is its frequent reliance on knowledge of the parameters of the stochastic process associated with the random coefficient. While engineers are often able to specify these parameters from direct physical information, econometricians are seldom so fortunate and the identification and estimation problems are much more severe in an economic context".

A second popular way for modeling regime change in monetary policy is by assuming that the interest rule coefficients change according to a Markov Switching process.

This type of model attracted a great deal of interest in recent econometric literature since introduced by Hamilton (1989) to study the business cycle in the US. The author treats the contraction and expansion phases of GDP as two states and assumes that the shifts between these two regimes are governed by a Markov Chain.

The Markov-chain process has offered a different set of useful time-varying parameter models that allow for discrete change of regimes driven by an unobservable state variable. For instance, Pagan and Schwart (1990) use this methodology to model the conditional volatility of stock returns. Sims (1999) uses the model of Hamilton (1989) to investigate the possibility of structural breaks in the conduct of monetary policy.

Sims and Zha (2006) consider various models with discrete regime changes both in the coefficients of the Taylor rule and variance of shocks to the economy using a Markov-Switching Vector Autoregression (MS-VAR) model. They show evidence of regime change in monetary policy that is driven by the time-varying variance of the shock rather than time variation in the parameters of the policy rule.

Similarly, Kuzin (2006) studies the possible change in the monetary policy of the Bundesbank's monetary targeting period (1975-1998) using the Markov-switching model and the Kalman filter. The main conclusion is that the Bundesbank's aversion to inflation was not constant over time and entails some structural changes.

Tan et al. (2010) use the specification of regime change in Hamilton (1989) in order to determine whether real output responds asymmetrically to monetary policy shocks in four Asian countries namely Indonesia, Malaysia, the Philippines and Thailand. Their study provides strong evidence that a contractionary monetary policy has a larger absolute impact than an expansionary policy.

The Markov-switching is an attractive way to model the succession of different regimes where the regime states are not imposed exogenously, but rather determined endogenously by the estimation procedure.

However, the problem with this discrete-break model is that it fails to account for gradual policy changes and may be misleading or inefficient in formulating policy advice in the case of regime shifts that do not fit properly into one of the considered regimes.

The Markov-switching model implies a sudden abrupt change. However, most economic variables move in a smooth manner, with transition from one regime to another taking some time. In addition, instantaneous changes in economic aggregates series are possible if all agents act simultaneously and in the same direction. However, in reality such participants react differently to economic events at slightly different times, making the Smooth Transition Regression (STR) model the best structural framework. 
Moreover, the STR model allows the data to dictate whether the regime change is abrupt or smooth unlike other regime switching models that require a prior assumption of abrupt switching between regimes. The STR models have several advantages over the Markov-switching regime models by allowing gradual evolution of the model's coefficients and do not impose restrictions on the way parameters vary over time. If a linear functional form were correct, the STR would exclude nonlinear effects and the linear specification outperforms the nonlinear one. Instead, if some nonlinearity exists, the STR technique allows one to choose both the appropriate switching variable and type of the transition function without entailing restrictions on the speed, the intensity and the persistence of the changes.

In the context of STR models there are two standard choices of the transition function: the logistic function and the exponential function. It is simple to depict the logistic STR (LSTR) and exponential STR (ESTR) models by employing the appropriate transition function in the STR model: logistic transition function for the LSTR model and exponential transition function for the ESTR model. The ESTR model suggests that reactions of agents to shock have rather similar magnitude with opposite signs. Then, this model implies a symmetric U-Shaped response around the threshold value.

Many factors such as market frictions as well as heterogeneous agents may include nonlinear and asymmetric adjustment of many macroeconomic and financial series which make ESTR models particularly applicable. Panos et al. (1997) support this view and employ the ESTR framework to analyze the dynamic behavior of deviation from Purchasing Power Parity and they argue that this model is ideal in cases where the dynamic behavior of a process is similar in both upswings and downswings. Subsequently, using an ESTR model, Chen and Wu (2000) report additional evidence of nonlinear price adjustment.

On the other hand, the logistic transition function has received considerable attention in the literature because it allows different dynamics to be present for low and high values of the threshold variable $S_{t}$. Thus, it offers advantage when modeling processes whose dynamic properties are different in expansions from what they are in recessions.

Furthermore, Teräsvirta and Anderson (1992) analyze the dynamic properties of industrial production indices of thirty OECD countries. They find strong nonlinearity in the industrial production dynamic of most of countries under scrutiny. The preferred model is the logistic STR, because it allows the business cycle indicator to switch between two distinct regimes smoothly.

Using Australian data, Teräsvirta et al. (1994) employ LSTR framework in order to examine nonlinearities over the business cycle.

Sarantis (2001) and McMillan (2001) support this view and advocate the use of the logistic as opposed to the exponential transition function. The S-shaped logistic function is more intuitive to bull and bear stock market regimes or recessions versus expansions, as opposed the U-Shaped exponential function which cannot be used to identify expansion or contraction behavior.

On the same track, Castro (2011) estimates a nonlinear policy rule for three central banks namely the Fed, the bank of England $(\mathrm{BoE})$ and the European central bank $(\mathrm{ECB})$. The results indicate that only the monetary behavior of the Fed can be well described by a linear Taylor rule. On the contrary, the BoE and ECB follow a nonlinear Taylor rule: they only react actively to inflation when it is above the target $(2.5 \%$ as a target point for the BoE and $[1.8 \%, 2.4 \%]$ as a target range for the ECB) and they only start to react to the business cycle when inflation is established well below the target.

Alcidi et al. (2011) describe the Federal Reserve reaction function during the Greenspan tenure as a LSTR model. Using this framework, they find that although linear Taylor rules describe well the broad contours of monetary policy, they fail to detect important changes in the policy stance in response to the stock market crash in 2000-2001 and the risk of hitting the zero lower bound of the yield curve in 2002-2003. 


\section{EMPIRICAL METHODOLOGY}

\subsection{Transmission Channels of Monetary Policy in Tunisia}

The effectiveness and reliability of monetary policy depends on the willingness of central banks to induce changes in aggregate demand. The route between monetary policy and aggregate demand operates through a variety of channels.

The Tunisian monetary policy is assumed to work mostly through three mechanisms namely interest rate channel, credit channel and exchange rate channel.

These three channels generally reinforce each others, all moving aggregate demand in the same direction. Then, changes in aggregate demand either stimulate or restrain the overall macroeconomy. This impact changes over time under different circumstances (Subprime Crisis, Tunisian revolution shock, successive transitional governments).

\subsubsection{Interest Rate Channel}

The main transmission channel is the effect that changes in the bank's interest rate have on sensitive components of aggregate demand such as consumption and investment.

A tightening of monetary policy may induce a greater cost of capital and lower yield on saving, which in turn leads to a reduction of spending decisions and demand for loans and other financial sources. As a result, over time, there is typically a cut back of aggregate economic activity. Despite the significant role played by the interest rate channel in the transmission of Tunisian monetary policy impulses prior the revolution the interest rate lost its central role in the adjustment of monetary conditions after the political events that unfold in Tunisia since the revolution on January 14, 2014. This is due to two reasons: first, within a context of political upheaval and security tensions, the lack of visibility makes firms insensitive to changes of interest rates in their investment strategy which explains the worsened investor's wait-and-see attitude.

Second, because of negative real interest rates, Tunisian households have deserted bank deposits in favor of real assets such as policy property and real estates.

In sum, these actors continue to be deaf to call for consumption and investment as a result of growing anxiety about the future.

\subsubsection{Credit Channel}

The credit channel was proposed as an enhancement to the traditional interest rate channel. It works as follows: a restrictive monetary policy leads to a drop in bank deposits, which in turn brings about a decrease in bank's willingness to give loans. This has a negative impact on aggregate demand as the decrease of bank credit causes a cut back on investment and consumption expenditures by bank dependent agents.

This channel occupies a place of honor after the revolution. Despite the substantial progress in the last few years the stock markets in Tunisia are still underdeveloped with a relatively small number of listed firms, low free-flat of shares and thin trading.

The negative impact is more pronounced in Tunisia as the corporate sector relies mostly on banks as the main external source of funds.

In particular, up to the revolution event, a global liquidity dried up (large cash withdrawals) and weakened the banking system. To circumvent possible credit crunch and insolvencies, the central bank had to provide commercial banks with liquidity, injecting the equivalent of TND 3.588 billions on December 2011 and the ratio of required reserve was cut down from $12.5 \%$ to $2 \%$. 


\subsubsection{Exchange Rate Channel}

The effect of changes in interest rate on the exchange rate has become increasingly important with the growing internationalization of economies throughout the world.

An exchange rate channel determines that a monetary expansion will translates into nominal depreciation of local currency.

As a result, a lower value of domestic currency makes domestic goods cheaper than foreign goods thereby sustaining competitiveness of the home economy and hence causing a rise in net exports and a stimulation of overall economic activity.

This channel has become increasingly important with the advent of revolution related events. Two main factors may explain the renewed interest in the role played by the exchange rate channel in the adjustment of monetary conditions. First, growth of monetary supply remains under control and does not represent a source of inflation (wage increase, smuggling, commodity prices increase). Then, monetary policy cannot act through interest rate adjustments to reduce inflation for instance.

Second, the Tunisian central bank attaches priority to exchange rate movements because of fear of the exchange rate pass-through effects.

Figure 1. Evolution of the transmission channels of the Tunisian monetary policy
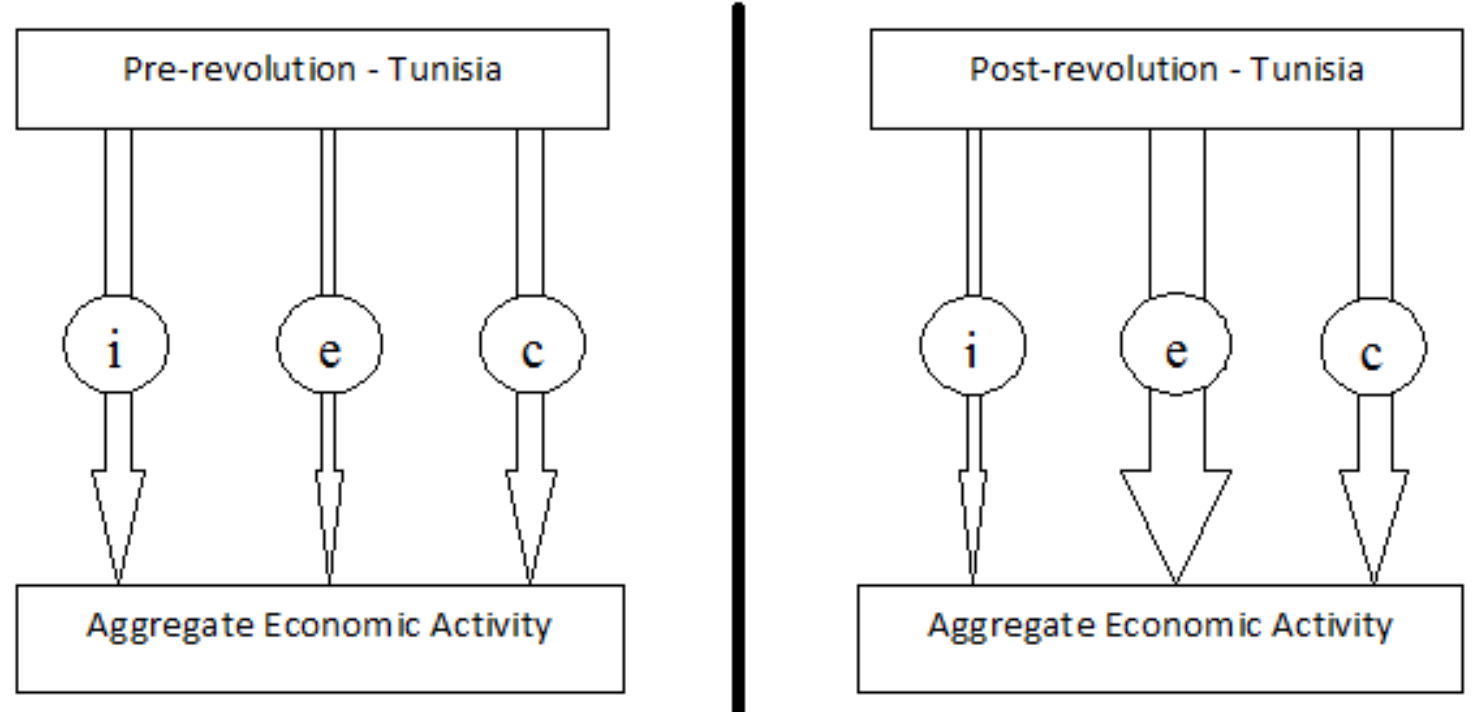

Figure 1 above depicts the change in the monetary policy channels in Tunisia after the revolution. Indeed, after January 14, 2011 the exchange rate channel becomes the most important channel followed by the credit channel and then the interest rate channel while during the pre-revolution era the design of the monetary transmission channel was completely different as the credit and interest rate channels were the most important channels. The exchange rate channel had a very little importance.

\subsection{Augmented Linear Taylor Rule}

Our starting point is the estimation of a linear symmetric Taylor rule for monetary policy in Tunisia. Despite its simplicity, this rule has fitted the data relatively well in the literature. Some studies extend this linear rule by considering the effect of additional variables in the conduct of monetary policy. Following Clarida et al (1998) and 
Rudebush (2002) among others, we augment the baseline specification by introducing the lagged interest rate that takes into account the inertia of monetary policy.

Clarida et al (1998) find that the interest rate smoothing parameter enters significantly in the Taylor rule. In fact, the reason of doing so is mainly due to fear to disturbing capital markets which are too sensitive to policy changes and could create financial instability via investors herding behavior, or the need to build consensus to support a policy change. We also augment the conventional Taylor rule by the real exchange rate. Similarly, Svensson (2003) proposes an extension of the Taylor rule by incorporating the exchange rate in a rule designed for small open economies. His conclusion is in line with that of Batini et al (2001) who show that the descriptive power of the Taylor rule augmented by the exchange rate is higher than the standard Taylor rule for small open economies (i.e: UK).

There are several reasons to include the REER in the Tunisian reaction function. The constant real effective exchange rate rule provides a buffer against shocks and helps to reduce volatility in interest rate. This policy is partly out of concerns for the international competitiveness of Tunisia's manufacturing exports. In particular, a rise in the REER implies a fall in competitiveness and vice versa.

When dealing with capital flows the authorities confront a trade-off between currency appreciation and depreciation. The former has a negative impact on the competitiveness of exports while the Tunisian dinar depreciation induces losses to Tunisian Central Bank by increasing the country massive debt burden, which is reflected in a higher debt service.

Indeed, the fall of the Tunisian dinar is well understood by pressure on the balance of payment which is still running a trade deficit: the dinar slippage has caused large spikes in the price of imports. However, exports have not benefited from improved price competitiveness due to the current Eurozone crisis, which has crippled European demand for Tunisian goods. In addition, the government instability went against mastering the social tensions and clarifying the investment outlook. In sum, the trade deficit has been deepened significantly to $10.65 \%$ of GDP in 2012 against $4.77 \%$ throughout the year 2010 .

Thus, the concept of REER goes beyond the weighted average of currencies to greater significance for Tunisian policymakers where sectors are expected to contribute more to the growth of the economy. Indeed, many researchers argue that real effective exchange rate has important effects not only on the general economic performance of a country and its international competitiveness but also on the different sectors of the economy.

Moreover, the Tunisian economic situation remains fragile because the level of foreign reserves, which is barely three months of imports, remains the lowest in the region and forced the Central Bank to pursue an active policy of rebuilding reserves.

Given the importance of exchange rate especially in the context of a small open economy, it is widely agreed to introduce it as an explanatory variable in the Taylor rule. To sum up, the inclusion of the REER is consistent with the objectives of the Tunisian Central Bank in terms of maintaining price stability.

The model thus becomes:

$$
i_{t}=\alpha+\rho i_{t-1}+b_{\pi} \pi_{t}+b_{y} y_{t}+b_{q} q_{t}+u_{1 t}
$$

where $\alpha=\mathrm{r}-\emptyset \pi^{*}$ and $\mathrm{b}_{\pi}=1+\emptyset$.

$i_{t}$ stands for the nominal short-term interest rate, $r$ for equilibrium real interest rate. $\pi_{t}$ is the inflation rate at time $t$, calculated from the consumer price index (CPI), reflecting cost of acquiring a fixed basket of goods and services by an average consumer. $y_{t}$ refers to the output gap, defined as the difference between actual output and potential output, which is measured using the Hodrick-Prescott filter. $q_{t}$ refers to the REER. 
$\varnothing$ indicates the sensitivity of interest rate policy to deviations of inflation from its target. $b_{y}$ represents the coefficient of the reaction of the central bank in response to output gap. $b_{\mathrm{q}}$ is the coefficient of reaction of the Central Bank to change in REER and $\rho$ measures the degree of interest rate smoothing.

\subsection{Nonlinear Taylor Rule}

Following the work of Teräsvirta (1998), the standard two-regime LSTR for a nonlinear Taylor rule could be derived as follows:

$$
i_{t}=\phi Z_{t}+\theta Z_{t} G\left(\gamma, c, S_{t}\right)+u_{t}, t=1, \&, T
$$

where $G\left(\gamma, c, S_{t}\right)=\left(1+\exp \left\{-\frac{\gamma}{\sigma_{S_{t}}^{k}} \prod_{k=1}^{k}\left(S_{t}-c\right)\right\}\right)^{-1}$ with $G\left(\_, c, S_{-} t\right)=1+\exp \left\{-\left(S_{-} t-c\right)\right\}^{\mathcal{M}}(-1),{ }_{-}>0$.

$\mathrm{Z}_{\mathrm{t}}=\left(\mathrm{w}_{\mathrm{t}}^{\prime}, \mathrm{x}_{\mathrm{t}}^{\prime}\right)$ is a vector of regressors including the exogenous variables, $\mathrm{x}_{\mathrm{t}}\left(1, \mathrm{x}_{1 \mathrm{t}}, \ldots, \mathrm{x}_{\mathrm{kt}}\right)$ and lagged dependent variable, $\mathrm{w}_{\mathrm{t}}\left(\mathrm{y}_{\mathrm{t}-1}, \ldots, \mathrm{y}_{\mathrm{t}-\mathrm{p}}\right)$.

The vectors $\varphi=\left(\varphi_{0}, \varphi_{1}, \ldots, \varphi_{\mathrm{n}}\right)$ and $\theta=\left(\theta_{0}, \theta_{1}, \ldots, \theta_{\mathrm{m}}\right)$ represent $\left((\mathrm{n}+1)^{*} 1\right)$ and $\left((\mathrm{m}+1)^{*} 1\right)$ parameter vectors in the linear and nonlinear parts of the model, respectively.

The disturbance term is iid with zero mean and constant variance, $\mathrm{u}_{\mathrm{t}} \approx \operatorname{iid}\left(\theta, \sigma^{2}\right)$.

$\mathrm{G}\left(\gamma, \mathrm{c}, \mathrm{S}_{\mathrm{t}}\right)$ is the transition function bounded by 0 and 1 , and depends upon the transition variable $\mathrm{S}_{\mathrm{t}}$, the slope parameter $\gamma$ and the location parameter $c$.

In terms of the above equation, the logistic function increases in tandem with the transition variable. Van Dijk et al. (2002) demonstrate that as $S_{t} \rightarrow 0($ or $\infty)$ the transition function becomes abrupt, such that the model becomes indistinguishable from the linear autoregressive model.

Teräsvirta (1994) proposes some procedures to build an LSTR model; these include linearity test, estimation and evaluation of the model. A linearity test is performed for the purpose of choosing the appropriate transition variable $\mathrm{S}_{\mathrm{t}}$ and the most suitable form of the transition function among LSTR1 (with a single transition variable), LSTR2 (with two transition variables) and ESTR model. In fact, the null hypothesis of linearity can be formulated as follows: the null hypothesis of linearity consists in testing $\mathrm{H}_{0}: \theta=0$ in Equation (2) against the alternative hypothesis of nonlinearity: $\mathrm{H}_{1}: \theta \neq 0$.

Luukkonen et al. (1988) argue that testing for linearity is not a straightforward task, due to the fact that the model is only identified under the alternative of nonlinearity. In particular, the parameters $c$ and $\theta$ are nuisance parameters and are not present under the null of linearity. Teräsvirta (1998) shows that this identification problem can be circumvented by approximating the transition function with a third Taylor expansion around $\gamma=0$. After reparametrization and rearrangement the approximation yields the following regression:

$$
\mathrm{i}_{\mathrm{t}}=\delta_{0}+\delta^{\prime} \tilde{\mathrm{Z}}_{\mathrm{t}}+\beta_{1}^{\prime} \tilde{\mathrm{Z}}_{\mathrm{t}} \mathrm{S}_{\mathrm{t}}+\beta_{2}^{\prime} \tilde{\mathrm{Z}}_{\mathrm{t}} \mathrm{S}_{\mathrm{t}}^{2}+\beta_{3}^{\prime} \tilde{\mathrm{Z}}_{\mathrm{t}} \mathrm{S}_{\mathrm{t}}^{3}+\mathrm{v}_{\mathrm{t}}
$$

Accordingly, the null hypothesis of linearity becomes: $\beta_{1}^{\prime}=\beta_{2}^{\prime}=\beta_{3}^{\prime}=0$ and a LM-type test with F-distribution is used to test this null hypothesis of linearity. Teräsvirta (1998) suggests a linearity test for each candidate transition variable. In terms of this approach, the variable with the lowest p-value (strongest rejection of linearity) is chosen as the transition variable.

Once the linearity is rejected against LSTR-type nonlinearity we follow Teräsvirta (2004) and consider the following three tests: 


$$
\mathrm{H}_{02}: \beta_{3}=0, \mathrm{H}_{03}: \beta_{2}=0 / \beta_{3}=0 \text { and }_{04}: \beta_{1}=0 / \beta_{2}=\beta_{3}=0
$$

The above test statistics are labeled $F_{2}, F_{3}$ and $F_{4}$, respectively $\mathrm{F}_{2}, F_{2}, F_{3}$ and $F_{4}$ are used to determine the number of regime shifts among LSTR1 and LSTR2. The decision rule is that the LSTR1 is chosen if the p-value of $\mathrm{H}_{04}$ or $\mathrm{H}_{02}$ is the lowest. Conversely, the LSTR2 is selected if the p-value of $\mathrm{H}_{03}$ is the lowest.

The chosen model can then be estimated and evaluated as outlined in Eitreheim and Teräsvirta (1996). Several misspecification tests are used in the STR literature, such as test of no remaining nonlinearity, test of no residual autocorrelation and test of parameter constancy. These tests will be carried out in the empirical section.

\section{DATA}

We use quarterly data over the period going from 1998:Q4 to 2013:Q4. The data series, which include the interest rate, inflation rate, output gap and REER are collected from the international Financial Statistic (IFS) and Bloomberg databases.

Figure 2 shows the time paths of all variables introduced in our model for Tunisia. Despite an unfavorable international environment characterized in particular by commodity price surge, the Tunisian government managed to keep inflation under control through the absence of significant shocks and a better management of monetary and fiscal policies. However, the BCT knows a persistent high rate of inflation following the revolution, the level surpassed $6 \%$ in early 2013. Several monetary and structural factors contributed to the rise of inflation rate.

In fact, during the period following Tunisia's January 2011 revolution, the Tunisian Dinar has depreciated against both the euro and the dollar. The symbolic threshold of two dinars to one Euro has been exceeded and the dinar to the dollar exchange rate is about 1.5 , historically the highest ever.

Figure 2. Time series dynamics

Inflation

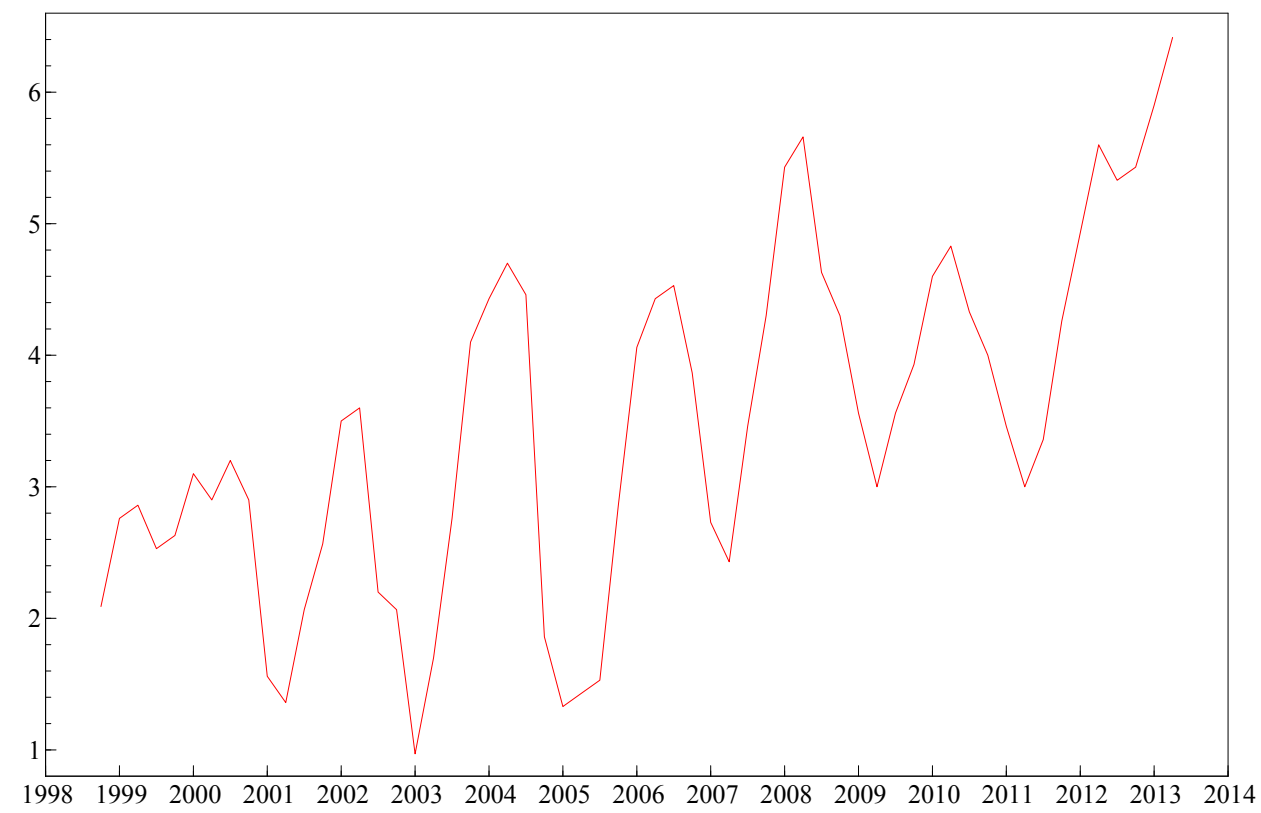




\section{Interest Rate}

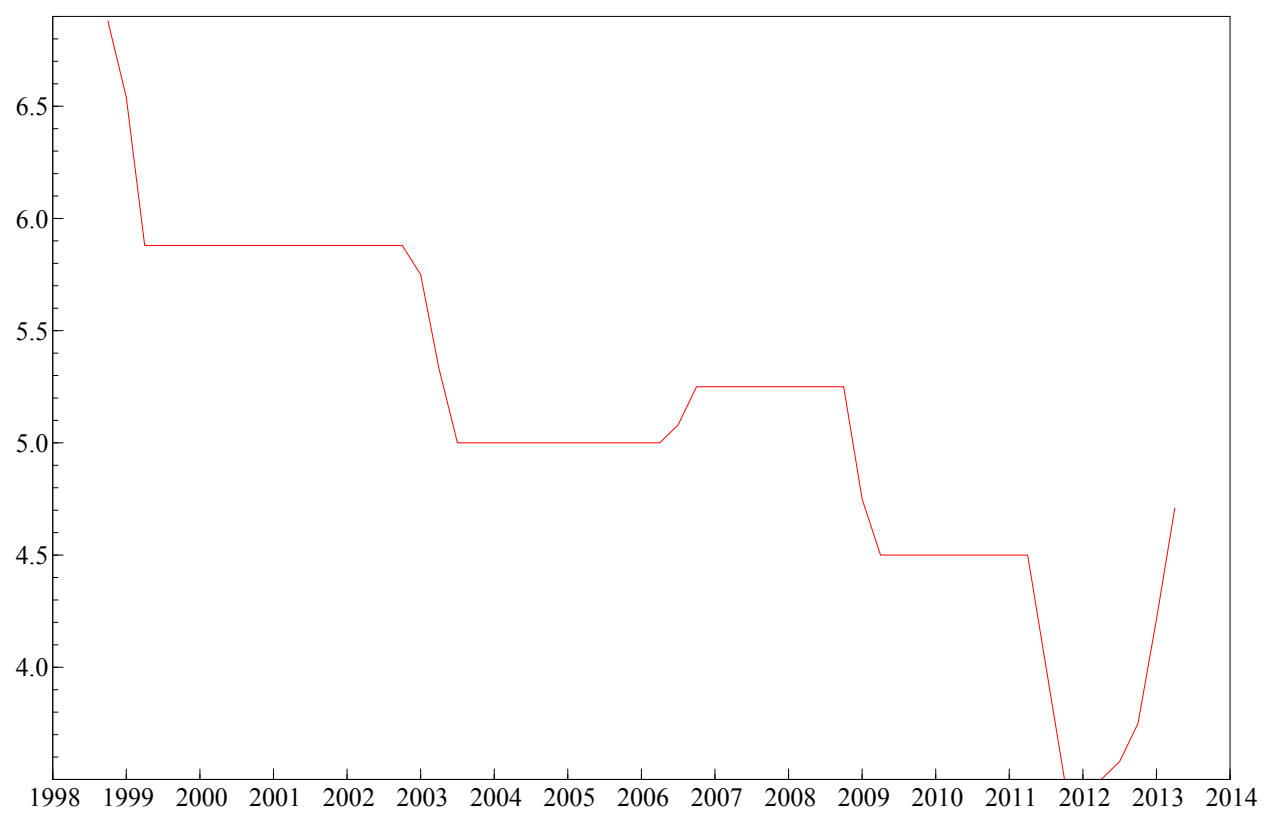

\section{REER}

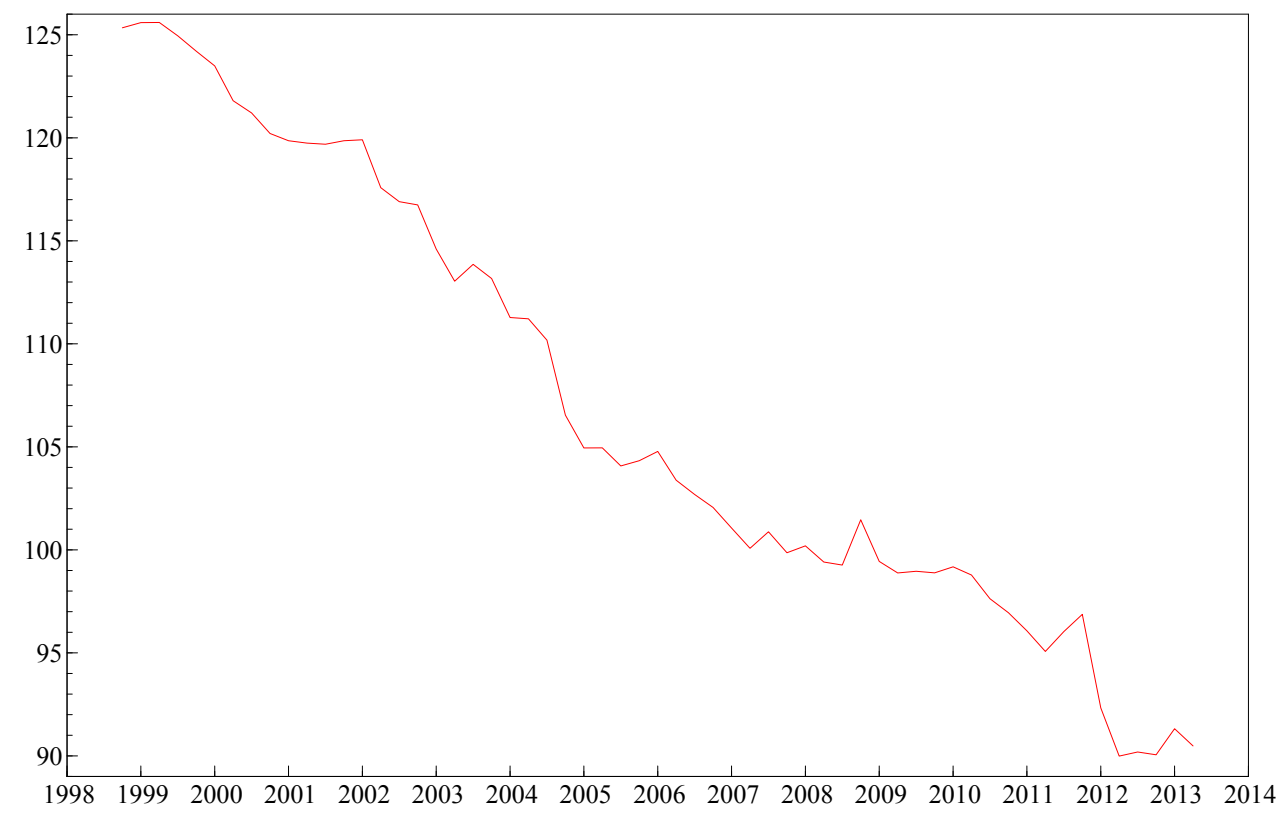




\section{Output Gap}

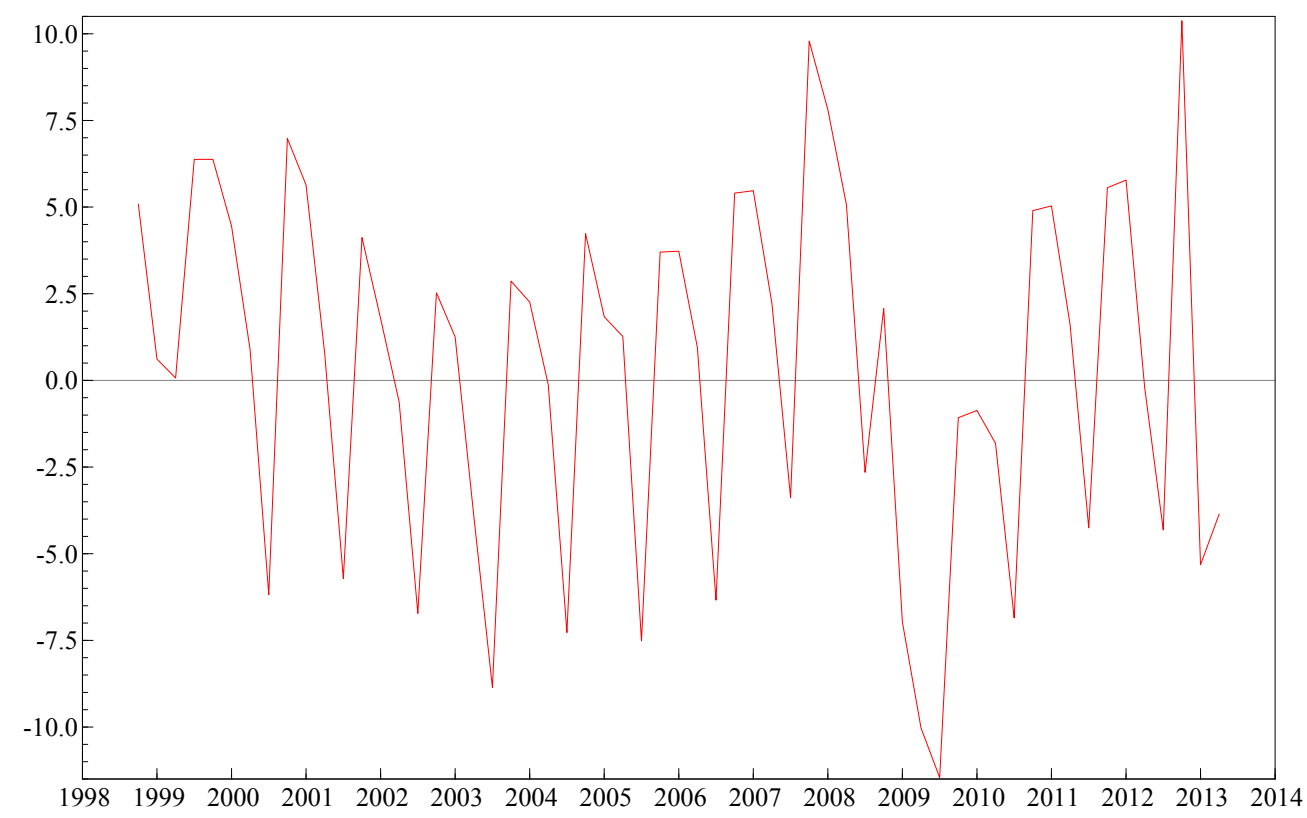

Thus, this drop in the Tunisian dinar value has generated inflationary pressures due to the price increase of certain imported goods especially the raw materials import and so firms will have to pass the increase of production costs on the sales prices. Also, the increase of imported product prices will increase demand for domestic goods which become relatively cheaper causing an increase in their prices.

Other monetary reason for the inflation rate hike is the adoption of an expansionary monetary policy aimed at reducing interest rate and make lower reserve requirement of the banks. The decline in interest rate is not without consequence on bank liquidity. To address this issue the BCT had to provide commercial banks with liquidity, injecting the equivalent of TND 3.588 Billion on December 2011 to stimulate demand in a context of scarcity of goods supply. This situation was aggravated by a backdrop of social demand and continuous protests to claim a rise in salaries that translated into an increase in producer prices, increased unemployment, significant decline in foreign investments and zero growth.

In addition, smuggling, trafficking and illegal export of subsidized foodstuffs across the Libya-Tunisia and AlgeriaTunisia borders are reported to be one of the major factors of food price inflation in Tunisia. Since the Libyan revolution, Libyans are mass buying from their neighbor, whose political unrest made its highly porous borders and a large part of Tunisian goods leave Tunisia in smuggling. Hence the shortage of Tunisian products usually available generates dangerous food inflation.

Moreover, before the estimation of equation 1, it is essential to check for the stationarity of the considered time series. The results of ADF and the Zivot- KPSS test are gathered in table 1. 
Table 1. Stationarity results

\begin{tabular}{lcccc}
\hline & $i_{t}$ & $\pi_{t}$ & $y_{t}$ & $q_{t}$ \\
\hline ADF & $-2.633^{* * *}$ & -0.4959 & $-4.66^{* * *}$ & $-3.702^{* * *}$ \\
KPSS & $0.6537^{* * *}$ & 0.948 & $0.0801^{* * *}$ & 1.9421 \\
ZA & $-7.626^{* * *}$ & -3.6865 & $-5.3419^{* * *}$ & $-6.3857^{* * *}$ \\
\hline
\end{tabular}

Note: This table reports the results of ADF, KPSS and Zivot-Andrews stationarity tests. $i_{t}, \pi_{t}, y_{t}$ and $q_{t}$ stand for interest rate, inflation rate, output gap and real exchange rate, respectively. $1 \%$ and 5\% Critical values for the ADF test are -2.56 and -1.94 whereas those of the KPSS test are 0.463 and 0.739 , respectively. $* * * * *$ and $*$ indicate significance at the $1 \%, 5 \%$ and $10 \%$ significance levels respectively.

The ADF test rejects the null hypothesis of unit root for $y_{t}, i_{t}, q_{t}$ at the $1 \%$ significance level. Consequently, the output gap, interest rate and REER are stationary. However, only the $\pi_{t}$ is not stationary and the hypothesis of the presence of unit root is not rejected. Likewise, the KPSS test fails to reject the null hypothesis of stationarity for the inflation and REER at the $1 \%$ significance level.

We also apply the Zivot-Andrews stationarity test which is robust to the presence of a structural break either in the mean, the trend or in both. Results of this test show that the null of unit root is strongly rejected for the interest rate, output gap and REER series while the inflation series is found to be nonstationary.

\section{RESULTS AND DISCUSSION}

\subsection{Linear Specification Results}

The estimation results of the linear Taylor rule augmented simultaneously by the lagged monetary policy and REER are presented in table 2 .

Table 2. Estimation results of linear augmented Taylor rule.

\begin{tabular}{|c|c|c|}
\hline & Estimate & std error \\
\hline$\alpha$ & 0.207 & 0.309 \\
\hline$b_{\pi}$ & $0.031^{*}$ & 0.0172 \\
\hline$b_{y}$ & $-0.0045^{* * *}$ & 0.0017 \\
\hline$\rho$ & $0.915^{* * *}$ & 0.0421 \\
\hline$b_{q}$ & $0.0053^{*}$ & 0.0042 \\
\hline $\begin{array}{l}\text { AIC } \\
R^{2}\end{array}$ & \multicolumn{2}{|c|}{$\begin{array}{l}-3.41 \\
0.945\end{array}$} \\
\hline $\mathrm{ARCH}(8)$ & 11.793 & {$[0.1607]$} \\
\hline
\end{tabular}

Note: This table reports the estimates of the linear Taylor rule augmented jointly by the lagged policy rate and the real exchange rate. p-values are between [ ]. ${ }^{* * *}, * *$ and $*$ indicate significance at the respective significance levels $1 \%, 5 \%$ and $10 \%$.

Results in Table 2 show that all estimates, except the intercept, are significant and have the expected signs. However, these coefficients are less than unity, which violates the stability condition in the Taylor rule. Additionally, according to the $\mathrm{R}^{2}$ criteria, we notice a good overall fit of the model. Also, there is no ARCH effect in the residuals of the estimated linear Taylor.

Inspection of the residuals series obtained from the estimation of the linear Taylor rule (Figure 2) reveals that the rule seems to capture well the behavior of decision makers. However, it is interesting to note that there are large residual spikes for more than one period notably in 1999-2000, 2003-2004, 2009 and 2011:Q4. The fitted interest rate is, over these time intervals, correlated and remarkably different from the actual value. 
Figure 3. Residual plot from Equation (1)

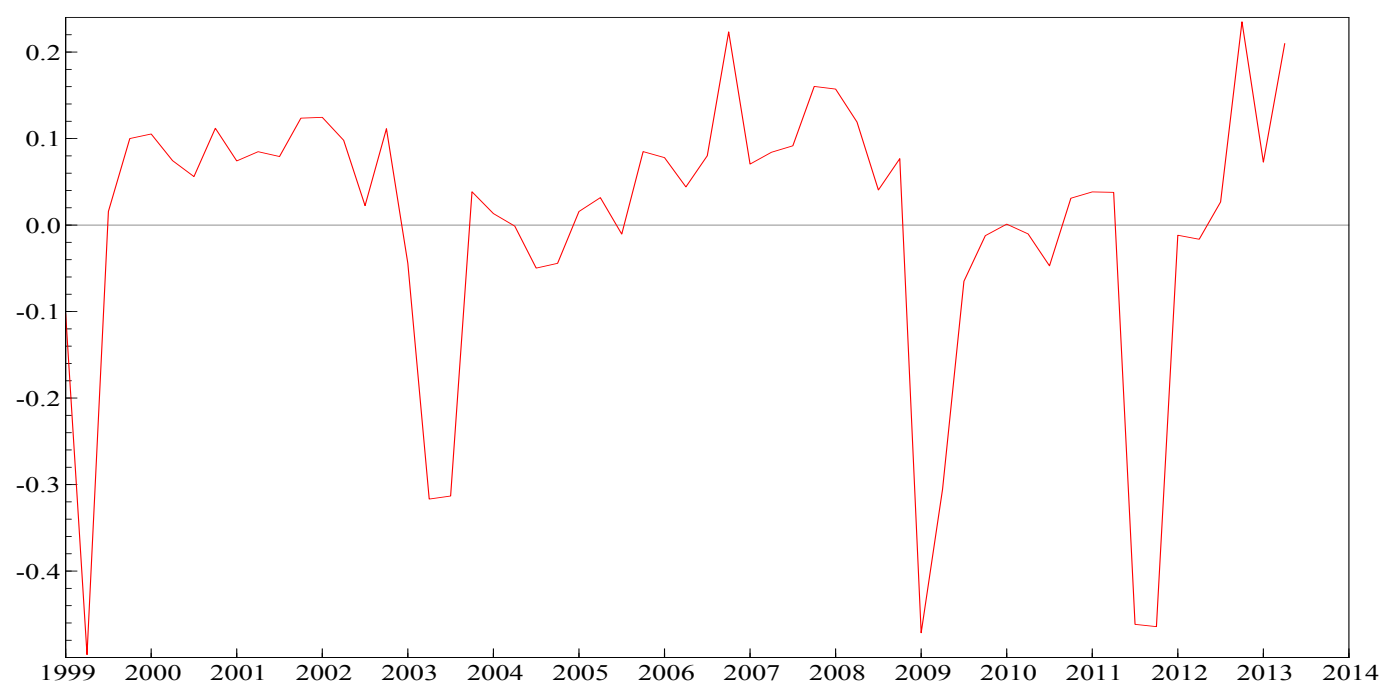

Negative (positive) residuals correspond to periods when the estimated rule leads to a higher (lower) interest rate than the actual ones. Accordingly, in such periods monetary policy appears to have been tightened (relaxed) beyond what was suggested by the inflation, the output gap, the lagged interest rate and the REER deviations. This could be explained by the fact that a linear Taylor rule even augmented is not able to perfectly describe the conduct of monetary policy in the presence of unusual contingencies (Alcidi et al, 2011).

Interestingly, this time spam coincides with periods where monetary policymakers had to face the presence of unexpected contingencies. For example, the period 1999-2000 was marked by the first multi-party presidential elections. However, the result was a victory for incumbent president at that time, who was reelected with $99.45 \%$ of the vote for his third term. This year marked a turning point in the recent history of Tunisia, the official terminology for the ousted president; opposition movement suffered from periodic crackdowns and the space for political dissent narrowed. In sum, the promises pledged soon proved to be futile and turned into real political mismanagement. So, the system should cope with a growing discontent within the country and a campaign of denunciation of international press organizations and human rights.

Similarly, the year 2003 has been marked by a substantial decline in tourist visits. The factors that have affected the Tunisian tourism, which is one of the most dynamic sectors of Tunisian economy, are manifold. The attack against Ghriba, the oldest synagogue in Africa, in which 20 people were killed and the Gulf war in 2003 led to a virtual paralysis of the tourism sector.

Further, although the Tunisian economy has not been directly affected by the fallout from the global Subprime crisis, given the limited financial exposure of the country, Tunisia has suffered from the collapse of purchasing power in Europe, its main economic partner (trade flows have been disrupted, the fall of income transferred from Tunisian worker's migrants living abroad, plummeting tourism revenues).

At last, after ousted president's departure in January 2011, Tunisian elected an interim National Constituent Assembly (NCA) charged with drafting Tunisian's new constitution. Since the possible arrival of Ennahdha (Islamic party) to power that may antagonize foreign aid donors and frighten capital investors, the country enters a recession; the GDP growth was around 3\% in 2010 and fell by nearly $-1 \%$ after the election.

In summary, we can deduce that although the linear Taylor rule describes well the broad contours of Tunisia's behavior, it fails to detect significant changes in policy direction in response to the unusual contingencies which affected the economy of Tunisia. Thus, the actual presence of finer monetary regimes corrupts the descriptive power of linear rules even augmented by the lagged policy rate and REER. 
The theoretical basis of the linear rule comes from the assumption that policymakers have a quadratic and symmetric loss function and that the aggregate supply or Phillips curve is linear. However, in reality, this assumption is unrealistic; monetary authorities may have asymmetric preferences (Surico, 2007) and the underlying aggregate supply schedule might be nonlinear leading to a nonlinear adjustment of the policy rate (Dolado et al, 2005).

Therefore, a nonlinear Taylor rule may be more appropriate to explain the behavior of monetary policy, and thus the adoption of a nonlinear specification instead of the linear one would leads to a better fit of the policy rate of the Tunisian Central Bank.

To get a deeper understanding of this phenomenon and investigate to what extent concerns of monetary policymakers are related to unexpected events, we adopt the LSTR model to test the hypothesis that the strength of the response of monetary policy to macroeconomic conditions depends on the level of risk facing the economy.

\subsection{Nonlinear Specification Results}

The results of the tests for the selection among transition variables candidates are reported in Table 3.

Table 3. Testing Linearity against STR results

\begin{tabular}{llllll}
\hline & \multicolumn{1}{c}{ F } & F2 & F3 & F4 & Selected Model \\
\hline$i_{t-1}$ & $3.7702 * 10^{-4}$ & $3.637 * 10^{-1}$ & $7.873 * 10^{-3}$ & $2.383 * 10^{-3}$ & LSTR1 \\
$y_{t}$ & $8.792 * 10^{-2}$ & $8.959 * 10^{-2}$ & $2.303 * 10^{-1}$ & $2.32 * 10^{-1}$ & Linear \\
$\pi_{t}$ & $1.4092 * 10^{-1}$ & $1.179 * 10^{-1}$ & $6.602 * 10^{-1}$ & $1.1439 * 10^{-1}$ & Linear \\
$q_{t}$ & $3.2244 * 10^{-2}$ & $2.457 * 10^{-1}$ & $7.5092 * 10^{-2}$ & $7.9037 * 10^{-2}$ & LSTR2 \\
\hline
\end{tabular}

Note: This table reports the results of the test of linearity against the STR nonlinearity. All numbers in this table are p-values associated with the test. All p-values are higher than $1 \%$ except the p-value associated to the lagged interest rate and hence linearity is rejected only for $\boldsymbol{i}_{t-1} . \mathrm{F}$ refers to the test of linearity against LSTR while, F2, F3 and F4 allow to select the adequate LSTR model among LSTR with one threshold (LSTR1) and LSTR with two thresholds (LSTR2).

Considering the above results, we conclude that there is strong evidence against the linear specification of the Taylor rule and that the past interest rate is likely to be responsible for nonlinear behavior of BCT. Thus, the parameter set changes whenever the interest rate drops below or rises above some threshold value.

This is consistent with Bruggemann and Riedel (2011) and Alcidi et al (2011) identification of transition variable. They identify and use the lagged interest rate as a threshold variable. Thus the switching between regimes is controlled by concerns about hitting the zero lower bound of the nominal interest rate where policy instrument does not respond in the usual way to its determinants.

An economy is said to be in a "liquidity trap" when short-term nominal interest rates are at a minimum and when money creation is no longer able to stimulate the economy by driving down interest rates. Liquidity trap is related to situations of uncertainty which create great anxiety about the future among economic actors. In such circumstances, nobody would be willing to lend, assuming zero storing costs for cash and nominally riskless zero rate of return.

This problem returned to prominence with the Great Depression in the US (1929-1930). It has been suggested that monetary policy was completely ineffective by then .i.e, a liquidity trap prevailed. Similarly, there has been substantial debate regarding the bank of Japan's (BoJ) monetary policy conduct during the 1990's and more recently with the Subprime crisis. In such situation, the Fed's traditional tools have been unable to provide further stimulus to the economy.

Tunisia is not excluded as its economy was also mired in a slump especially after the revolution of 2011 . The first post revolution days were characterized by simultaneous sharp drops in demand and supply, accompanied by serious disturbances in the production system (sit-in, social unrest with strikes). Similarly, this period was marked by a sharp decline in foreign currency assets, down under the combined effect of the fall in the number of tourists visiting the country and exports of phosphates. 
All these factors have led to a major shock reflected through the exceptional decline in real GDP growth. This brings the Tunisian economy to move into a situation of liquidity trap when cuts in policy rate seem to have little or no impact of hick-starting demand and output [reduce twice its interest rate to 50 basis points each in June and September 2011].

This decline in interest rates failed to encourage the economic actors to lend money. These actors continue to be deaf to calls for consumption and investment as a result of growing anxiety about the future.

The test for the choice of the transition function is also presented in the Table 3. It indicates that an LSTR1 model fits better the Tunisian monetary policy. This model is often used to capture the asymmetric behavior of the business cycle in the sense that booms and busts are characterized by different dynamics [Teräsvirta and Anderson, 1992].

Furthermore, equation (2) describes the model to be estimated with lagged interest rate as the selected threshold variable, which splits the sample into two regimes. Thus, the resulting detailed nonlinear LSTR model to be estimated is reported in equation (4) below.

$$
i_{t}=\alpha_{1}+\rho_{1} i_{t-1}+b_{\pi, 1} \pi_{t}+b_{y .1} y_{t}+b_{q .1} q_{t}+\left(\alpha_{2}+\rho_{2} i_{t-1}+b_{\pi .2} \pi_{t}+b_{y, 2} y_{t}+b_{q, 2} q_{t}\right) G\left(\gamma, c, i_{t-1}\right)
$$

LSTR model estimation results are reported in table 4.

Table 4. Estimation results of LSTR model

\begin{tabular}{|c|c|c|}
\hline & Linear Part & Nonlinear Part \\
\hline Intercept & $\begin{array}{c}4.808 \\
(2.949)\end{array}$ & $\begin{array}{l}-3.655 \\
(2.9137)\end{array}$ \\
\hline$i_{t-1}$ & $\begin{array}{c}0.892 * * * \\
(0.0367)\end{array}$ & $\begin{array}{l}-0.393 \\
(0.2885)\end{array}$ \\
\hline$y_{t}$ & $\begin{array}{l}-0.007 * * * \\
(0.002)\end{array}$ & $\begin{array}{l}0.019 * * * \\
(0.006)\end{array}$ \\
\hline$\pi_{t}$ & $\begin{array}{c}0.077 \\
(0.115)\end{array}$ & $\begin{array}{c}0.068 \\
(0.134)\end{array}$ \\
\hline$q_{t}$ & $\begin{array}{l}-0.046 \\
(0.036) \\
\end{array}$ & $\begin{array}{c}0.061 \\
(0.038) \\
\end{array}$ \\
\hline$\gamma$ & & \\
\hline$c$ & & \\
\hline AIC & & \\
\hline$R^{2}$ & & \\
\hline Jarque-Bera & & \\
\hline$A R C H(8)$ & & \\
\hline
\end{tabular}

Note: This table reports the estimates of the nonlinear Taylor rule. Standard errors are between () and p-values are between [ ]. ***,** and $*$ indicate significance at the respective significance levels $1 \%, 5 \%$ and $10 \%$.

Table 4 confirms our conjectures; the estimates clearly reveal the existence of two regimes. The first regime is very close to the linear augmented rule reported in Table 2 while the second (that we will call the low interest rate regime) is at odds with the classical Taylor rule. It clearly shows the existence of a special regime that applies only to unusual economic conditions, in response to which central banks change their usual policy conduct.

Results in Table 4 show that the BCT reacts differently to the REER, the inflation rate and the output gap. This means that when the interest rate falls below the threshold value of $4.708 \%$; monetary policy enters the liquidity trap regime where the policy instrument does not respond in the usual way to its determinants. 
The transition speed parameter is statistically significant and has an estimated value equal to 3.45 indicating an abrupt change from one regime to another. Indeed, the estimated inflation coefficients $b_{\pi .2}<b_{\pi .1}$ support our earlier intuition from 2011 onward; the response to inflation over liquidity trap period has dropped dramatically and has become largely insignificant and we also notice that the Taylor principle is not satisfied in both regimes, the estimated coefficient on inflation is always lower than one, which indicates an accommodative behavior of interest rate to inflation.

We also note that $b_{y, 2}>b_{y .1}$ indicating an asymmetric response from the BCT to the output gap: the response to output gap over liquidity trap period suggests an upward movement.

A plausible explanation is that for low values of interest rate, the monetary authority is concerned about the effect of recession rather than the inflation level.

The results also reveal that $\rho_{2}<\rho_{1}$, that is, an accommodative response to the inertia of monetary policy during liquidity trap, which is consistent with Mishkin's view that considers when macroeconomic risk is high, policy in this setting tends to respond aggressively. For this reason, the degree of inertia in such cases tends to be lower than in more routine circumstances.

Also $b_{q .2}>b_{q .1}$ suggesting that the BCT pays close attention to the REER when setting its policy rate.

Therefore, the nonlinear estimates indicate that the BCT policymakers use some discretion in post-2011 era as the revolution has led to a shift from inflation stabilization to output stabilization.

In order to better appreciate the gain in terms of fit obtained by leaving the linear rule for the nonlinear specification we plot in figure 3 both the residuals from the augmented linear Taylor rule and the nonlinear specification. We notice that allowing for the functional form to deviate from a constant parameter Taylor rule allows describing well the broad contours of monetary policy conduct especially in periods of special regime and reveals less autocorrelation of the residuals. Indeed, such special regimes refer to some special circumstances in which policy makers extensively use their judgment to make decision.

Figure 4. Residual plot from the linear and LSTR models.

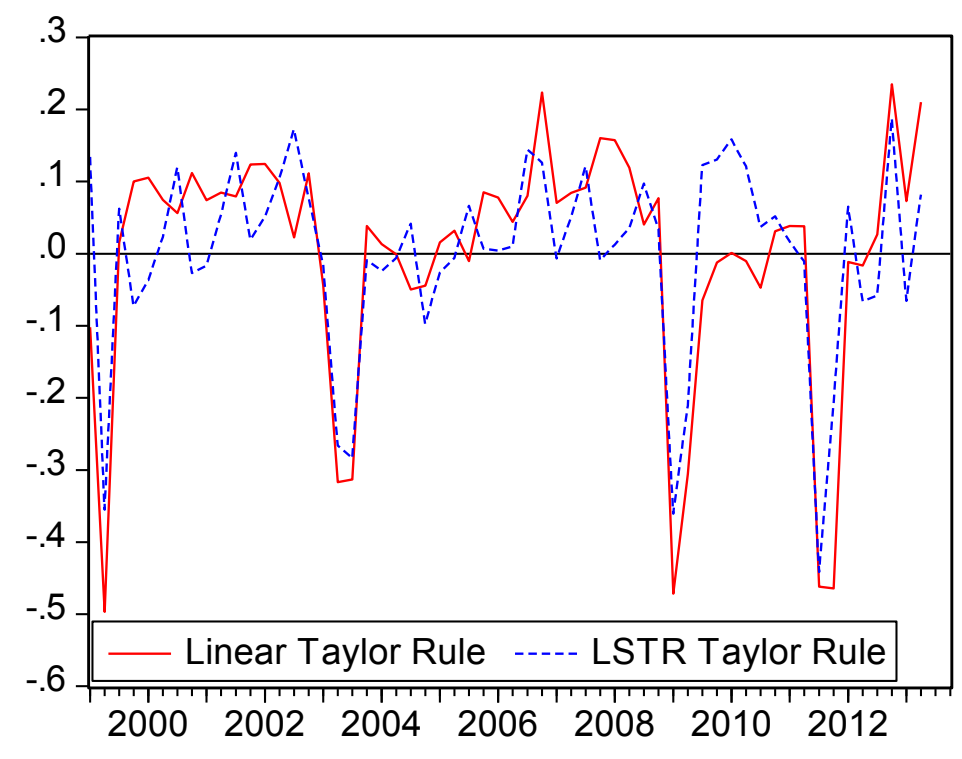


From these results, we can see although the linear rule describes well the broad contours of monetary policy of the BCT; it fails to detect significant changes in policy direction following the first multi-party presidential in 2011. These finding suggest that adopting a nonlinear specification instead of the linear one leads to a reduction in errors of 150 basis points in 1999, 2009 and 60 basis points in October 2011.

So far, this paper has provided evidence that it is possible to characterize the behavior of the BCT as a two-state Taylor rule, with different coefficients depending on whether the interest rate is below or above an estimated threshold value. This means that when the interest rate falls below that value, monetary policy enters the special regime (liquidity trap). These special regimes require disconnection from the automatic pilot rule of the Central Bank and policymakers should extensively use their judgments to make decision.

To better appreciate this similarity, the figure below illustrates the transition variable and the estimated threshold.

Figure 5. Transition variable using the estimated threshold

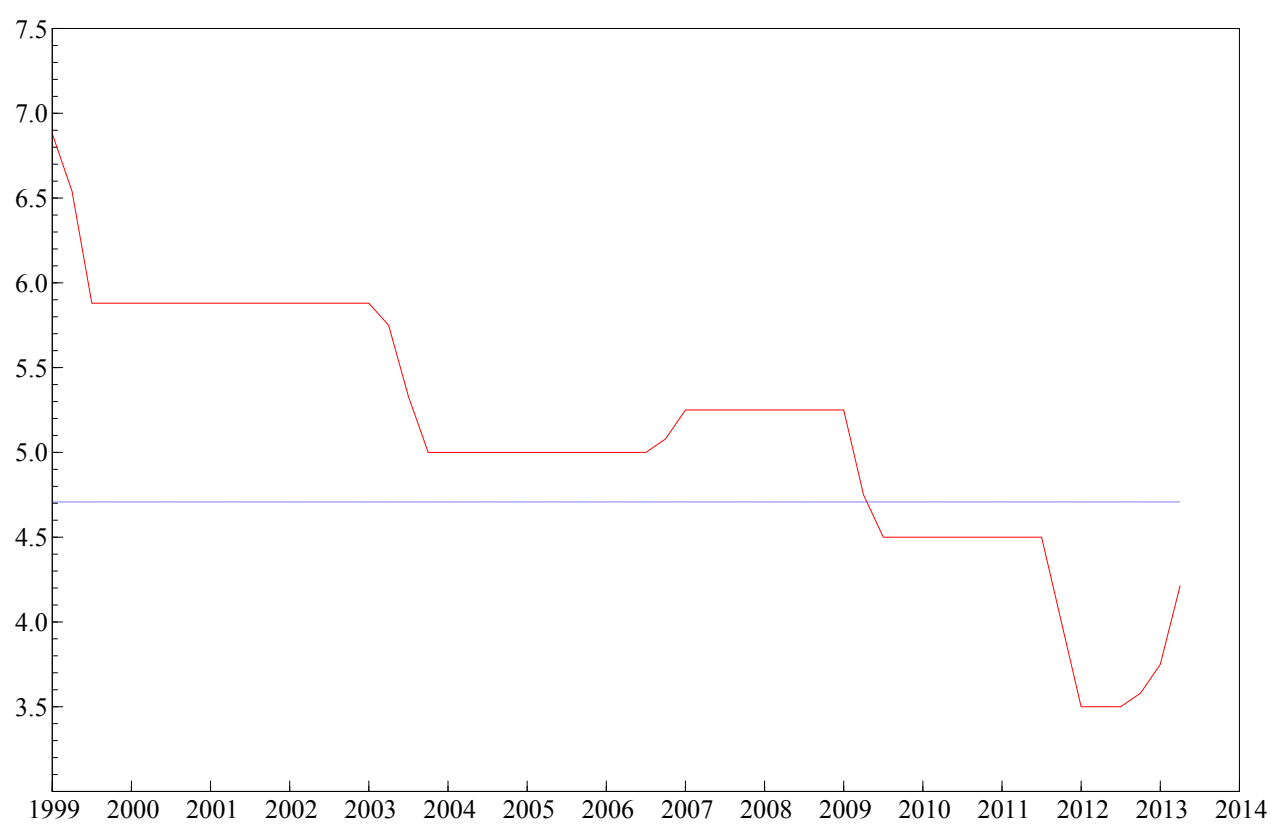

By looking at the transition variable using the estimated threshold plot, we can identify the timing of the policy switching. A stronger response regime takes place when the interest rate approaches the edges of liquidity trap band, especially from 2009 onward. Estimated threshold value splits the sample into two distinct periods of time. The shorter regime can be seen as a finer regime that applies only to unusual economic conditions where the policy instrument does not respond in the usual way to its determinants. The other one can be interpreted as the general regime that is at odds with the former one and associated with the normal economic conditions.

The Subprime crisis and the political events that unfolded in Tunisia since the $14^{\text {th }}$ January 2011 revolution took its toll on the Tunisian economy. Then, thinking that cuts in policy interest rate contribute to kick-start an economy mired in slump, the Tunisian monetary authority used unconventional policy tools to manage monetary policy; ensuring sufficient liquidity level to boost the recorded slowing economic growth; adjusting reserve requirements and interventions in the foreign exchange market. This decline in interest rates failed to get out the economic actors of their reserves. These actors continue to be deaf to calls for consumption and investment as a result of growing anxiety about the future. Tunisia today is in a significant "liquidity trap" that monetary policy alone cannot solve. It is important to institute stimulus programs to reassure economic actors and restore confidence in and about the future. 
Overall, this section concludes that the nonlinear models outperform the linear ones in the sense that the linear specification, by imposing a unique constant regime over the entire sample, fails to capture the special events and unexpected contingencies respectively, with the first multi-party presidential elections in 1999 and the first truly free election in 2011.

We perform misspecification tests to check for the robustness of our results and determine whether there is evidence of parameter instability, non normality of residuals, and remaining nonlinearity. These tests have been proposed by Eitrheim and Teräsvirta (1996). The results of these tests are presented in Table 5.

Table 5. Diagnostic tests results

\begin{tabular}{|c|c|c|c|c|}
\hline \multicolumn{5}{|l|}{ Parameter constancy test results } \\
\hline Transition Variable & \multicolumn{2}{|c|}{ F-statistic } & \multicolumn{2}{|c|}{ p-value } \\
\hline $\mathrm{H} 1$ & \multicolumn{2}{|c|}{1.8391} & \multicolumn{2}{|c|}{0.1015} \\
\hline $\mathrm{H} 2$ & \multicolumn{2}{|c|}{1.8854} & \multicolumn{2}{|c|}{0.0688} \\
\hline $\mathrm{H} 3$ & \multicolumn{2}{|c|}{2.36} & \multicolumn{2}{|c|}{0.0275} \\
\hline \multicolumn{5}{|c|}{ No remaining nonlinearity test results } \\
\hline Transition Variable & $\mathbf{F}$ & F2 & F3 & F4 \\
\hline$T A O(t-1)$ & $1.85 * 10^{-4}$ & $6.41 * 10^{-2}$ & $8.876^{*} 10^{-2}$ & $5.939 * 10^{-4}$ \\
\hline
\end{tabular}

Note: This table reports the diagnostic tests of parameter constancy and no remaining nonlinearity.

The results of diagnostic tests indicate the absence of $\mathrm{ARCH}$ effects in the residuals. Moreover, the remaining nonlinearity test shows that some of the nonlinearity was absorbed by an LSTR model with two regimes. So, we come to find evidence for the validity of our empirical nonlinear model. In addition, the parameter constancy test shows that the parameters do not vary over time if we consider the two first functional forms suggested by Eitrheim and Teräsvirta (1996). These various results therefore confirm the idea that the monetary policy followed by the BCT exhibits a strong nonlinearity.

\section{CONCLUSION}

This paper has shed more light on challenging the suitability of the nonlinear Taylor rule in characterizing the behavior of the Tunisian Central Bank, especially in abnormal times.

Obviously, in a context dominated by uncertainty, the evolution of monetary policy over a long period may entail structural changes in the behavior of monetary authorities. The failure to take into account these changes may bias the results. This is why the recent literature tries to take asymmetry into account.

Building on this view, this paper has provided evidence that it is possible to characterize the behavior of the Tunisian Central Bank as two-state Taylor rule with different coefficients depending on whether the interest rate is below or above the estimated threshold value of $4.708 \%$. This means that when the interest rate falls below that value, monetary policy enters the finer regime (liquidity trap). These finer regimes require involving a range of judgment factors that cannot be included in a parametric approach when setting monetary policy decision.

Overall, the evolution of coefficients reveals a richer picture of the Tunisian Central Bank conduct and is consistent with historical macroeconomic events. This is in accordance with our finding stating the adoption of an appropriate nonlinear approach instead of a linear one leads to a reduction in errors of 150 basis points in 1999, 2009 and 60 basis points in 2011 .

\section{AUTHOR BIOGRAPHY}

Yosra Baaziz is an assistant researcher at FSEG Mahdia, Tunisia. Her research focuses on the study of monetary policy in emerging countries.

David Heller is an assistant professor of finance at ISC Paris Business School, France. His research areas include Finance and Accounting. 
Moez Labidi is a professor of economics at the University of Monastir, Tunisia. His research focuses on the study of monetary policy in emerging markets. He has published his recent articles in referred journals such as Economic Modelling and Journal of Applied Business Research.

Amine Lahiani is an associate professor of Economics at the University of Orléans, France. His research interests include the study of long memory models and threshold models. His published several papers in International Journal of Forecasting, Economic Modelling, Energy Economics, Energy Policy, Journal of International Financial Markets, Institutions \& Money.

\section{REFERENCES}

Akerlof, G., 1970. The Market for 'Lemons': Quality uncertainty and the market mechanism. Quarterly Journal of Economics. 84(3), 488-500.

Alcidi, C., Flamini, A., Fracasso, A., 2011. Policy regime changes, judgment and Taylor rules in the Greenspan Era. Economica. 78, 89-107.

Ball, L., 1999. Efficient rules for monetary policy. International finance. 2(1), 63-83.

Barro, R., Gordon, D., 1983. Rules, discretion and reputation in a model of monetary policy. Journal of Monetary Economic. 12(1), 101-121.

Batini, N., Harrison, R., Millard, S.P., 2001. Monetary policy rules for an open economy. Paper Presented at the Federal Reserve Bank of San Francisco Conference.

Belsley, D.A., Kuti, E., 1973. Time-varying parameter structures: An overview. Annals of Economic and Social Measurement. 2, 375-79.

Bernanke B., 2003. "A perspective on inflation targeting. Remarks at the Annual Washington Policy Conference on the National Association of Business Economists, Washington D.C.

Bernanke, B., Mishkin, F.S., 1997. Inflation targeting: A new framework for monetary policy?. Journal of Economic Perspectives. 11(2), 97-116.

Bernanke, B., Woodford, M., 1997. Inflation forecasts and monetary policy. Journal of Money, Credit and Banking. 24, 653-684.

Boivin, J., 2006. Has U.S. monetary policy changed? evidence from drifting coefficients and real-time data. Journal of Money, Credit and Banking. 38(5), 1149-1173.

Bruggemann, R., Riedel., J., 2011. Nonlinear interest rate reaction functions for the UK. Economic Modelling. 28, 1174-1185.

Castro V., 2011, "Can central banks' monetary policy be described by a linear (augmented) Taylor rule or by a nonlinear rule?. Journal of Financial Stability. 157, 228-246.

Chen, S.L., Wu, J.L., 2000. A re-examination of purchasing power parity in Japan and Taiwan. Journal of Macroeconomics. 22(2), 271-284

Clarida, R., Galí, J., Gertler M., 1998. Monetary policy rules in practice: Some international evidence. European Review. 4(6), 1033-1067.

Clarida, R., Gale, J. Gertler, M., 2000. Monetary policy rules and macroeconomic stability: Evidence and some theory. Quarterly Journal of Economics. 115, 147-180.

Conrad, C., Eife, T.A., 2012. Explaining inflation gap persistence by a time-varying Taylor rule. Journal of Macroeconomics. 74, $59-75$.

Dolado, J., Dolores, R., Naveira, M., 2005. Are monetary policy reaction functions asymmetric? The role of nonlinearity in the Phillips Curve. European Economic Review. 49, 485-503.

Eitrhem, Ø., Terasvirta, T., 1996. Testing the adequacy of smooth transition autoregressive models. Journal of Econometrics. 74 , $59-75$.

Elkhoury, M., 2006. A time-varying parameter model of a monetary policy rule for Switzerland. The case of the Lucas and Friedman hypothesis. HEI Working Papers 01-2006.

Friedman, M., 1959. A program for monetary stability. Fordham University Press.

Judd, J.P., Rudebusch, G.D., 1998. Taylor's rule and the Fed: 1970-1997. Federal Reserve Bank of San Francisco Economic Review. 3, 3-16.

Hamilton, J.D., 1989. A new approach to the economic analysis of non-stationary time series and the business cycle. Econometrica. 57, 357-84.

Kim, C.J., Nelson, C.R., 2006. Estimation of a forward-looking monetary policy rule: a time-varying parameter model using expost data. Journal of Monetary Economics. 53(8), 1949-1966.

Kolman, F., 2013. The asymmetric reaction of monetary policy to inflation and the output gap: evidence from Canada. Economic Modeling. 30, 911-923.

Kuzin, V., 2006. The inflation aversion of the Bundesbank: a state-space approach. Journal of Economic Dynamics and Control. 30(9-10), 1671-1686.

Kydland, F., Prescott, E., 1977. Rules rather than discretion: the inconsistency of optimal plans. Journal of Political Economy. 85, 473-91. 
Lee, D.J., Son, J.C., 2013. Nonlinearity and structural breaks in monetary policy rules with stock prices. Economic Modeling. 31, $1-11$.

Luukkonen, R., Saikkonen, P., Teräsvirta, T., 1988. Testing linearity against smooth transition autoregressive models. Biometrika. 75, 491-499.

Mandler, M., 2007. The Taylor rule and interest rate uncertainty in the U.S 1955-2006. MPRA Paper N 2340.

Mankiw, G., 1990. A quick refresher course in macroeconomics. Journal of Economic Littérature. 28, 1645-1660.

McCallum, B.T., 1988. Robustness properties of a rule for monetary policy. Carnegie-Rochester Conference Series on Public Policy. 29, 173-204.

McMillan, D.G., 2001. Nonlinear predictability of stock market returns: evidence from non-parametric and threshold models. International Review of Economics and Finance. 10, 353-368.

Mishkin, F.S., 1999. International experiences with different monetary policy regimes. Journal of Monetary Economics. 43(3), 579-606.

Mishkin, F.S., 2011. Monetary policy strategy lessons from the crisis. NBER Working Paper $\mathrm{N}^{\circ} 16755$.

Olsen, E., Enders, W., Vohar, E., 2012. An empirical investigation of the Taylor curve. Journal of Macroeconomics. 32, $392-404$.

Orphanides, A., 2004. Monetary policy rules, macroeconomic stability and inflation: a view from the trenches. Journal of Money, Credit and Banking. 36(2), 151-175.

Pagan, A., Schwert, G.W., 1990. Alternative models for conditional stock volatility. Journal of Econometrics. 45, 267-290.

Panos, M., Nobay, A.R., Peel, A.D., 1997. Transactions costs and nonlinear adjustment in real exchange rates: an empirical investigation. Journal of Political Economy. 105, 862-879.

Romer. D, 2000. Keynesian macroeconomics without LM curve. Journal of Economic Perspectives. 14(2), 149-169.

Rudebusch, G.D., 2002. Term structure evidence on interest rate smoothing and monetary policy inertia. Journal of Monetary Economics. 49, 1161-1187.

Sarantis, N., 2001. Nonlinearities, cyclical behaviour and predictability in stock markets: international evidence. International Journal of Forecasting. 17, 459-482.

Sims, C.A., 1999. Drift and breaks in monetary policy. Princeton University. Mineo

Sims, C.A., Zha, T., 2006. Were there regime switches in US monetary policy?. American Economic Review. 96(1), 54-81.

Stiglitz, J., 2000. The contributions of the economics of information to twentieth century economics. Quarterly Journal of Economics. 115(4), 1441-1478.

Surico, P., 2007. The Fed's monetary policy rule and US inflation: the case of asymmetric preferences. Journal of Economic Dynamics and Control. 31, 305-324.

Svensson, L.E.O., 2003, What is wrong with Taylor rules? Using judgment in monetary policy through targeting rules. Journal of Economic Literature. 42, 426-477.

Tan, S.H., Habibullah, M.S., Khong, R.W.L., 2010. Non-linear unit root properties of stock prices: evidence from India, Pakistan and Sri Lanka. Economics Bulletin. 30(1), 274-281.

Taylor, J.B., 1993. Discretion versus policy rules in practice. Carnegie-Rochester Conference Series on Public Policy, 195-214.

Taylor, J.B., 1999b. Monetary Policy Rules. NBER Conference Report Series, University of Chicago Press, Chicago and London.

Taylor, J.B., 1999. An historical analysis of monetary policy rules. Taylor J. B. (Ed.) Monetary Policy Rules, Chicago: University of Chicago Press.

Terasvirta, T., 1994. Specification, estimation and evaluation of smooth transition autoregressive models. Journal of the American Statistical Association. 89, 208-218.

Teräsvirta, T., 1998. Modelling economic relationships with smooth transition regressions. In: Ullah, A., Giles, D.E. (Eds.) ”, Handbook of Applied Economic Statistics. Marcel Dekker Inc., NY, 507-552 (Chapter 15).

Teräsvirta, T., 2004. Smooth transition regression modelling. In: Lutkepohl, H., Kratzig, M. (Eds.) ”, Applied Time Series Econometrics. Cambridge University Press, 222-242 (chapter 6).

Teräsvirta, T., Anderson, H.M., 1992. Characterizing nonlinearities in business cycles using smooth transition autoregressive models", in Nonlinear Dynamics, Chaos and Econometrics, Edited by Pesaran M.H.and Potter S.M., pp.111-128.

Teräsvirta, T., Tjфstheim, D., Granger, C.W.J., 1994. Aspects of modelling nonlinear time series. In: Engle, R.R.,McFadden, D. (Eds.), Handbook of Econometrics, 4. Elsevier, Amsterdam.

Trecroci, C., Vassalli, M., 2006. Monetary policy regime shifts: new evidence from time-varying interest rate rules. University of Brescia, Department of Economics Discussion Paper $N^{\circ} 0602$.

Van Dijk, D., Teräsvirta, T., Franses, P.H., 2002. Smooth transition autoregressive models- a survey of recent developments. Econometric Reviews. 21(1), 1-47. 


\section{NOTES}

